\title{
Effects of the New Prokinetic Agent DA-9701 Formulated With Corydalis Tuber and Pharbitis Seed in Patients With Minimal Change Esophagitis: A Bicenter, Randomized, Double Blind, Placebo-controlled Study
}

\author{
Chan Hyuk Park, ${ }^{1}$ Hyun-Soo Kim $^{2}$ and Sang Kil Lee ${ }^{1 *}$ \\ ${ }^{1}$ Division of Gastroenterology, Department of Internal Medicine, Severance Hospital, Institute of Gastroenterology, Brain Korea 21 PLUS project \\ for Medical Science, Yonsei University College of Medicine, Seoul, Korea; and ${ }^{2}$ Division of Gastroenterology and Hepatology, Department of \\ Internal Medicine, Yonsei University Wonju College of Medicine, Wonju, Gangwon-do, Korea
}

\begin{abstract}
Background/Aims
DA-9701 (Motilitone) is a new prokinetic agent formulated with Corydalis Tuber and Pharbitis Seed. We assessed the efficacy of DA-9701 in symptomatic patients with minimal change esophagitis.
\end{abstract}

\section{Methods}

Patients with minimal change esophagitis presenting with reflux or dyspeptic symptoms were randomly assigned to receive either DA-9701 $30 \mathrm{mg}$ or placebo t.i.d. (means 3 times a day). After 4 weeks of treatment, the primary efficacy end point determined by changes of the Nepean dyspepsia index questionnaire-Korean version (NDI-K) symptom scores, was analyzed.

\section{Results}

Forty-two and 39 patients were assigned to the treatment and control groups, respectively. After 4 weeks, NDI-K symptom scores were reduced from 35.4 to $13.5(P<0.001)$ and from 43.0 to $27.7(P<0.001)$ in the treatment and the control groups, respectively. However, changes in the symptom scores did not differ between the 2 groups $(P=0.741)$. Although the quality of life scores were significantly improved after 4 weeks in both groups, changes in the quality of life score between the baseline value and that at 4 weeks did not differ between the 2 groups. The reflux symptom score was significantly im proved in the treatment group compared to the placebo group in patients aged 65 years or older $(P=0.035)$.

Received: February 19, 2014 Revised: March 11, 2014 Accepted: March 18, 2014

(c) This is an Open Access article distributed under the terms of the Creative Commons Attribution Non-Commercial License (http://creativecommons. org/licenses/by-nc/3.0) which permits unrestricted non-commercial use, distribution, and reproduction in any medium, provided the original work is properly cited.

*Correspondence: Sang Kil Lee, MD, PhD

Division of Gastroenterology, Department of Internal Medicine, Yonsei University College of Medicine, 50 Yonsei-ro,

Seodaemun-gu, Seoul 120-752, Republic of Korea

Tel: +82-2-2228-1996, Fax: +82-2-393-6884, E-mail: sklee@yuhs.ac

Financial support: None.

Conflicts of interest: None.

Author contributions: Hyun-Soo Kim and Sang Kil Lee, conception and design; Chan Hyuk Park and Sang Kil Lee, analysis and interpretation of the data, drafting of the article; Hyun-Soo Kim and Sang Kil Lee, critical revision of the article for important intellectual content; All authors, final approval of the article.

ORCID: Sang Kil Lee, http://orcid.org/0000-0002-0721-0364. 


\section{Conclusions}

Although NDI-K symptom scores and quality of life scores were improved after 4 weeks of treatment compared with baseline values in patients with minimal change esophagitis, DA-9701 did not improve the symptom scores or quality of life scores compared with the placebo.

\section{(J Neurogastroenterol Motil 2014;20:338-346)}

\section{Key Words}

DA-9701; Minimal change esophagitis; Motilitone; Non-erosive reflux disease

\section{Introduction}

Non-erosive reflux disease (NERD) is defined as the presence of troublesome reflux-associated symptoms and the absence of mucosal breaks at endoscopy. ${ }^{1}$ Endoscopic findings in NERD patients can be classified into normal findings and minimal change esophagitis. ${ }^{2-6}$ Minimal change esophagitis is determined by a characteristic appearance of the distal end of the esophageal mucosa that includes a whitish appearance and/or erythema, and/or erosion that is not regarded as a mucosal break. ${ }^{5,6} \mathrm{~A}$ previous study that included 25,536 individuals who underwent upper gastrointestinal endoscopic examinations as a health check-up showed that minimal change esophagitis was closely related with reflux symptoms including heartburn and acid regurgitation. ${ }^{3}$ Minimal change esophagitis, however, was also associated with dyspeptic symptoms including globus sensation and epigastric soreness. ${ }^{3,7}$ In addition, NERD is very common in the primary care setting, and it adversely affects the quality of life. ${ }^{1,8,9}$ Proton pump inhibitors (PPIs), which are used mainly for treating erosive esophagitis, are also commonly used in the treatment of NERD. ${ }^{10-12}$ However, PPIs are less effective in NERD patients than in erosive esophagitis patients. ${ }^{13-16}$ In addition, hiatal hernia is less common and gastric atrophy is more severe in patients with minimal change esophagitis than in those with erosive esophagitis. ${ }^{13,17}$ These findings suggest that the characteristics and pathophysiology of minimal change esophagitis differ from those of erosive esophagitis. As part of an effort to improve the symptoms of NERD patients, some studies on prokinetics were conducted. ${ }^{9}$ Because prokinetics showed efficacy in patients with erosive esophagitis, its effect in patients with NERD was assessed. A randomized study, however, demonstrated that addition of mosapride to omeprazole was not more effective than omeprazole alone. ${ }^{18}$ Another study showed that remission of symptoms was maintained in fewer than half of patients with NERD who were receiving cisapride. ${ }^{19}$ An effective treatment option for NERD patients has not been identified to date.

DA-9701, a newly developed prokinetic agent, has been commercially produced under the name Motilitone in the Korea since early $2012 .^{20}$ DA-9701 is formulated with Corydalis Tuber and Pharbitis Seed. Both of these plants have been used in Oriental traditional medicine for the management of gastrointestinal symptoms. Corydalis Tuber, the root of Corydalis yahusuo W.T. Wang (Corydalis Tuber, Papaveraceae), has analgesic and antiulcer effects. ${ }^{21-23}$ In addition, Pharbitis Semen, the seed of Pharbitis nil Choisy, is believed to have analgesic effects on the abdomen. ${ }^{20}$ DA-9701 has shown affinity for the dopamine (D) 5-hydroxytryptamine $(5-\mathrm{HT})_{4}, 5-\mathrm{HT}_{1 \mathrm{~A}}$ and $5-\mathrm{HT}_{1 \mathrm{~B}}$ receptors. ${ }^{24-26}$ It has antagonistic effects on the $\mathrm{D}_{2}$ receptors and agonistic effects on the $5-\mathrm{HT}_{4}, 5-\mathrm{HT}_{1 \mathrm{~A}}$ and $5-\mathrm{HT}_{1 \mathrm{~B}}$ receptors. Thus, DA-9701 can improve delayed gastric emptying and may be effective as a prokinetic agent. ${ }^{20,27}$ On the other hand, DA-9701 increases basal gastric volume and gastric accommodation to a meal in animal models. ${ }^{21,26}$ Whereas other existing prokinetics lead mainly to gastric emptying, DA-9701 may have effects on both gastric emptying and gastric accommodation. Accordingly, DA-9701 is considered as a complex motility agent, which can be a solution to resolve the various symptoms of functional dyspepsia. In addition, DA-9701 may decrease gastroesophageal reflux via these mechanisms. It may help to improve both dyspepsia and reflux symptoms in patients with minimal change esophagitis.

\section{Materials and Methods}

\section{Design and Participants}

The present study was a doubleblind, placebo-controlled study with concealed allocation in symptomatic patients with minimal change esophagitis conducted at 2 university hospitals. Patients with gastrointestinal symptoms including reflux and 
dyspepsia symptoms for more than 3 months in a period of 6 months prior to enrollment who visited the outpatient clinics of the participating hospitals were invited to participate in this study. Symptoms were confirmed through patient interviews. Patients were required to have upper gastrointestinal endoscopy within 1 month of enrollment and were selected for the study if minimal change esophagitis was noted. Minimal change esophagitis was defined as the presence of one of the following characteristics at the distal end of the esophageal mucosa: whitish change and/or erythema, and/or erosion not regarded as mucosal break. ${ }^{5,6}$ Patients were also required to be aged 20 years or older, and to be outpatients at the relevant center.

Patients who had apparent causes of gastrointestinal symptoms such as gastric ulcer, malignancy, pancreatitis, biliary disease, irritable bowel syndrome and/or inflammatory bowel disease were excluded. Patients with a history of intra-abdominal surgery were also excluded. Furthermore, patients who had been treated with prokinetics, histamine $\mathrm{H}_{2}$ receptor antagonists, or PPIs within 1 month prior to the start of the study were excluded. Finally, any patients who were pregnant, lactating and/or who were attempting to become pregnant were excluded, as well as patients who were regarded by the study investigators as not to be suitable for participation.

All patients gave their written informed consent to participate in the study. The institutional review board of each center approved this study.

\section{Randomization and Treatment}

Randomization was achieved by using a computerized random number table with the key code securely stored. Random number table was created by one of the investigators ( $\mathrm{CHP}$ ) by applying a block randomization method with a block size of 6 . Patients were randomized to one of the 2 study arms. The patients in the treatment arm received DA-9701 (Motilitone, Dong-A Pharm., Co., Seoul, Korea) 30 mg t.i.d. (means 3 times a day) for 4 weeks. The patients in the control arm received placebo tablets that were identical to the DA-9701 tablets t.i.d. for 4 weeks. The following concomitant medications were prohibited: prokinetics, $\mathrm{PPIs}, \mathrm{H}_{2}$ receptor antagonists, non-steroidal anti-inflammatory drugs, corticosteroids and/or anti-cholinergics.

\section{Safety Assessment}

Safety profiles were assessed by using review of systems and physical examination at screening and at each outpatient clinic

Table. Baseline Patient Characteristics

\begin{tabular}{|c|c|c|c|}
\hline & Treatment group & Control group & $P$-value \\
\hline Patients (n) & 42 & 39 & \\
\hline Age $($ mean $\pm \mathrm{SD}, \mathrm{yr})$ & $48.4 \pm 13.9$ & $48.5 \pm 13.0$ & 0.978 \\
\hline $\operatorname{Sex}(\mathrm{n}[\%])$ & & & 0.643 \\
\hline Male & $13(33.3)$ & $12(28.6)$ & \\
\hline Female & $26(66.7)$ & $30(71.4)$ & \\
\hline Body mass index (mean $\left.\pm \mathrm{SD}, \mathrm{kg} / \mathrm{m}^{2}\right)$ & $22.4 \pm 2.7$ & $23.3 \pm 3.3$ & 0.195 \\
\hline Cigarette smoking (n [\%]) & & & $>0.999$ \\
\hline Current smoker & $4(10.3)$ & $4(9.5)$ & \\
\hline Ex-smoker & $2(5.1)$ & $3(7.1)$ & \\
\hline Never smoker & $33(84.6)$ & $35(83.3)$ & \\
\hline Alcohol use (n [\%]) & $14(35.9)$ & $13(31.0)$ & 0.637 \\
\hline \multicolumn{4}{|l|}{ NDI-K symptom score $($ mean $\pm \mathrm{SD})$} \\
\hline Dyspeptic symptom score & $30.0 \pm 12.8$ & $34.5 \pm 14.2$ & 0.138 \\
\hline Reflux symptom score & $5.4 \pm 5.0$ & $8.5 \pm 6.7$ & 0.024 \\
\hline Total score & $35.4 \pm 14.3$ & $43.0 \pm 16.0$ & 0.028 \\
\hline \multicolumn{4}{|l|}{ NDI-K quality of life score (mean \pm SD) } \\
\hline Interference & $77.9 \pm 18.1$ & $78.5 \pm 17.5$ & 0.868 \\
\hline Knowledge/control & $69.9 \pm 17.2$ & $68.5 \pm 20.6$ & 0.740 \\
\hline Eating/drinking & $73.2 \pm 21.0$ & $76.9 \pm 20.3$ & 0.422 \\
\hline Sleep & $78.3 \pm 22.1$ & $77.2 \pm 20.5$ & 0.829 \\
\hline Total score & $75.1 \pm 17.3$ & $75.4 \pm 17.7$ & 0.936 \\
\hline
\end{tabular}

NDI-K, Nepean dyspepsia index questionnaire-Korean version. 
visit. Laboratory tests including a complete blood count, biochemistry and electrolytes were performed before and after the treatment.

\section{Nepean Dyspepsia Index}

The patients' symptoms and quality of life were assessed by using the Nepean dyspepsia index questionnaire-Korean version (NDI-K). ${ }^{28}$ The NDI-K consists of a symptom checklist and a disease-specific quality of life measure. The symptom indexes of the NDI-K were rated for frequency (scored 0-4), intensity (scored 0-5) and bothersomeness (scored 0-4). The higher numbers represented the worsening of each symptom. Among the 15 items of the NDI-K symptom checklist, we used 8 and 2 items that represent dyspepsia and reflux, respectively. In addition, quality of life scores were obtained by using the NDI-K quality of life scale, which consists of 25 items, with a total score ranging from 0 to 99 . The NDI-K quality of life scale measures the quality of life in four domains: interference (13 items), knowledge/control (7 items), eating/drinking ( 3 items) and sleep (2 items).

\section{Patients' and Investigators' Global Assessment}

After 4 weeks of treatment, patients rated the efficacy of the drug by completing a self-reported questionnaire with a 7-point Likert scale ranging from "no response" to "complete response." Patients who reported the efficacy of the drug as "no response" or "slight response" were classified as non-response group, while others that reported the efficacy as higher than "slight response" were classified as response group. In addition, investigators assessed whether the patients were improved or not after 4 weeks of treatment.

\section{Study Endpoint}

The primary endpoint for the study was the changes of NDI-K symptom score of 8 dyspeptic and 2 reflux symptoms at week 4 . In addition, the following secondary endpoints were assessed: NDI-K symptom scores of 2 reflux symptoms and changes from baseline, NDI-K quality of life scores and changes from baseline, and the patients' and investigators' global assessment. As an exploratory data analysis, subgroup analyses for elderly patients aged 65 years or older were performed.

\section{Statistical Methods}

For comparison of continuous variables between the 2 groups, the $t$ test was used. Paired data including changes in NDI-K symptom scores and NDI-K quality of life scores from the baseline within each group were compared by using the paired $t$ test. Categorical variables were analyzed by using the $\chi^{2}$ test and Fisher's exact test. In addition, the differences in NDI-K symptom scores and NDI-K quality of life scores between the treatment and the control groups were adjusted for baseline values by using analysis of covariance.

The efficacy of DA-9701 was determined by using the intention-to-treat analysis. The last observation carried forward method was used to impute missing values of the efficiency endpoints. A value of $P<0.05$ was regarded as a significant difference for comparisons between groups. All statistical procedures were conducted by using the statistical software SPSS for Windows (version 18.0; SPSS Inc., Chicago, IL, USA).

\section{Results}

\section{Baseline Characteristics}

Of 81 patients enrolled in the study between August 2012 and July 2013, 42 and 39 were assigned to the treatment and control groups, respectively. Table shows the baseline patient characteristics including baseline NDI-K symptom scores and quality of life scores. The mean age was 48.4 and 48.5 years in the treatment and control groups, respectively $(P=0.978)$. The proportion of male patients was $33.3 \%$ and $28.6 \%$ in the treatment and control groups, respectively $(P=0.643)$. Body mass index, cigarette smoking and alcohol use did not differ between the 2 groups. Although the NDI-K dyspeptic symptom scores did not differ between the 2 groups, the reflux symptom scores were higher in the control group than in the treatment group $(P=$ 0.024). The total symptom scores were also higher in the control group than in the treatment group $(P=0.028)$. The NDI-K quality of life scores in 4 domains and the total quality of life scores did not differ between the 2 groups.

\section{Effects on the Nepean Dyspepsia Index Questionnaire-Korean Version Symptom Score}

The total scores of NDI-K were significantly improved after 4 weeks compared with the baseline values in both groups (baseline vs. week 4 : DA-9701, $35.4 \pm 14.3$ vs. $13.5 \pm 11.1, P$ $<0.001$; placebo, $43.0 \pm 16.0$ vs. $27.7 \pm 14.4, P<0.001)$ (Fig. 1). However, DA-9701 did not show a significant change 
compared with placebo $(22.0 \pm 13.6$ vs. $27.8 \pm 14.4, P=$ 0.741 ). Figure 2 shows the NDI-K symptom scores corresponding to 2 reflux symptoms. Along with the results of the total NDI-K symptom scores, the NDI-K reflux symptom scores were significantly improved after 4 weeks compared with the baseline values in both groups. However, changes in the reflux symptom scores between the baseline values and those at week 4 did not differ between the treatment and control groups $(P=0.573)$ (Fig. 2).
A

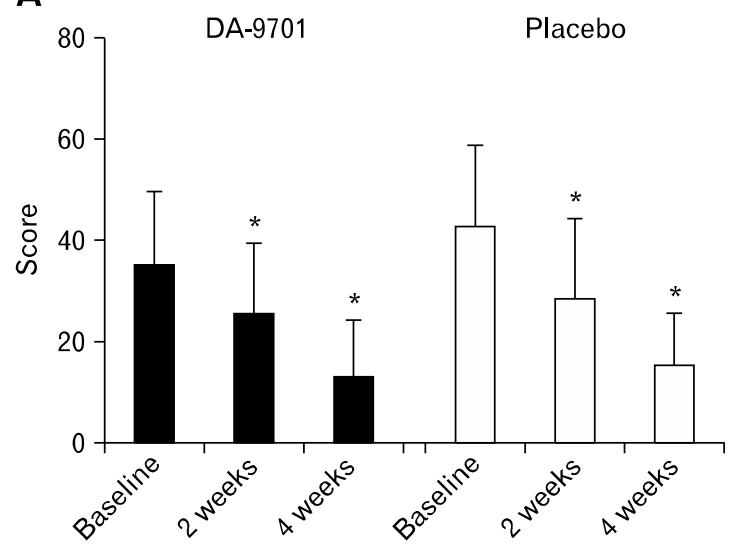

A

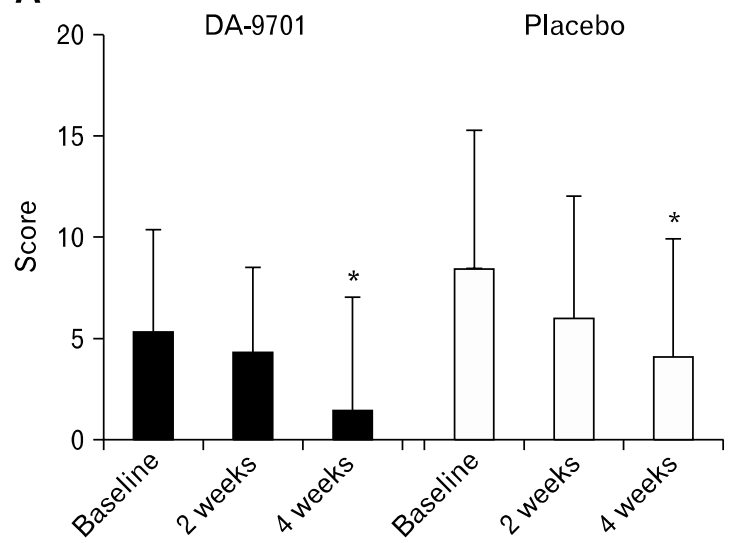

A

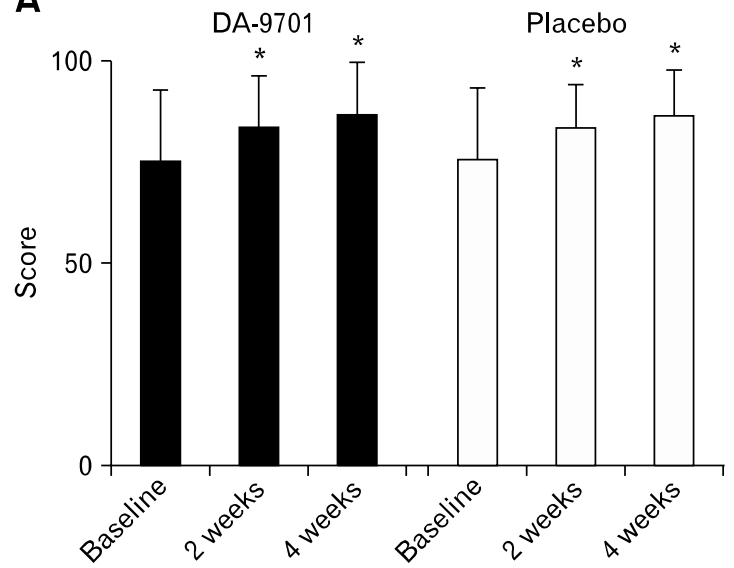

B

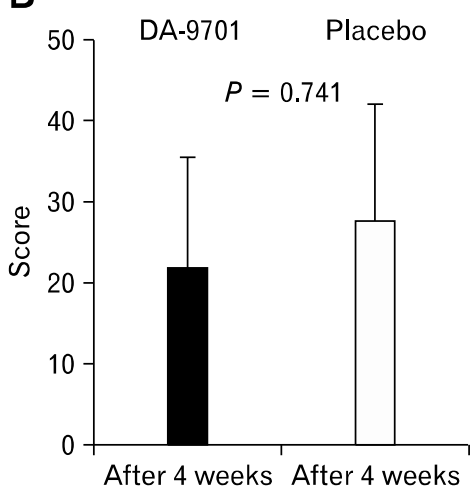

Figure 1. Total scores of the Nepean dyspepsia index questionnaire-Korean version symptom index including 8 dyspeptic symptoms and 2 reflux symptoms (A) and changes from baseline (B). ${ }^{*} P<0.05$ compared with score at baseline in each group.

B

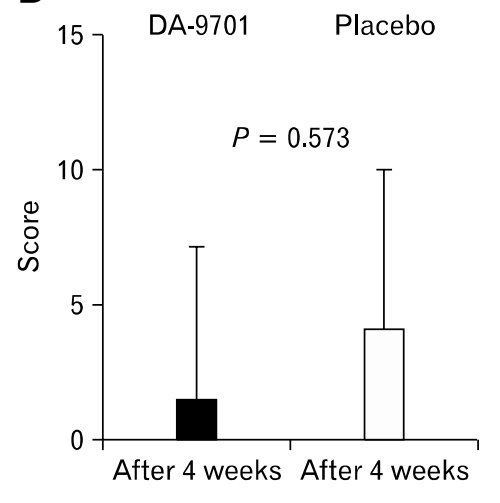

Figure 2. Nepean dyspepsia index questionnaire-Korean version symptom scores of 2 reflux symptoms (A) and changes from baseline (B). ${ }^{*} P<0.05$ compared with score at baseline.

B

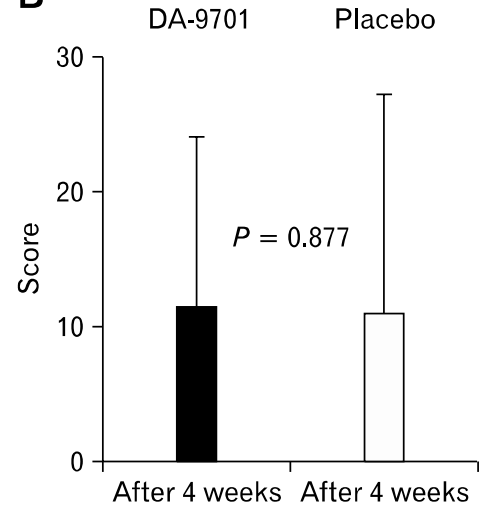

Figure 3. Nepean dyspepsia index questionnaire-Korean version quality of life scores (A) and changes from baseline (B). ${ }^{*} P<0.05$ compared with score at baseline in each group. 


\section{Effects on the Nepean Dyspepsia Index Questionnaire-Korean Version Quality of Life Score}

Figure 3 shows the NDI-K quality of life scores and changes from baseline. The quality of life scores were significantly improved after 4 weeks in both groups (baseline vs. week 4: DA-9701, $75.1 \pm 17.3$ vs. $86.6 \pm 13.6, P<0.001$; placebo, $75.4 \pm 17.7$ vs. $86.4 \pm 11.6, P<0.001)$. The quality of life scores for 4 domains (interference, knowledge/control, eating/drinking and sleep) were significantly improved in both treatment and control groups (data not shown). However, changes in the quality of life scores between the baseline values and those at week 4 did not differ between the 2 groups $(P=0.877)$.
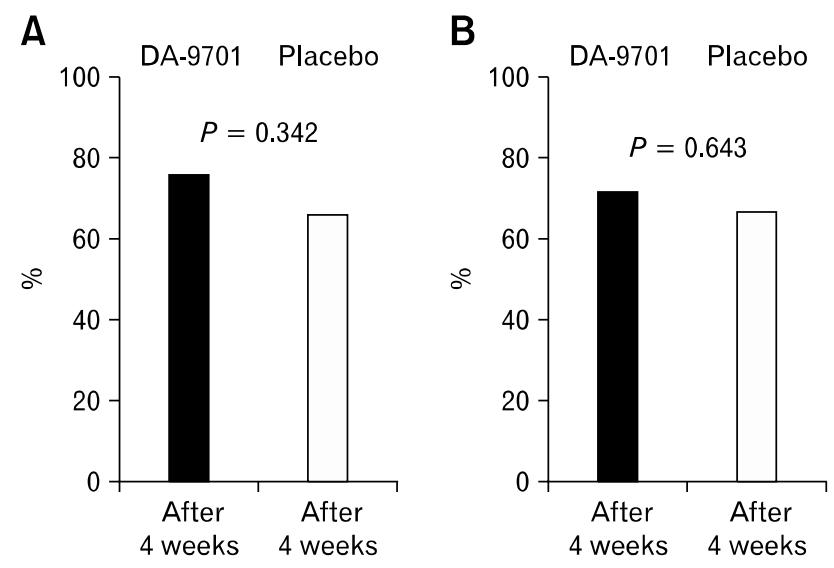

Figure 4. Percentage of patients who showed a response to the drugs according to the patients' (A) and investigators' global assessment (B).

\section{Patients' and Investigators' Global Assessment}

Percentages of patients who showed a response to the drugs according to the patients' and the investigators' global assessments are shown in Figure 4A and 4B, respectively. The percentages of patients whose symptoms were improved after 4 weeks of treatment did not differ between the 2 groups (DA-9701 vs. placebo; patients' assessment, $76.2 \%$ vs. $66.7 \%, P=0.342$; investigators' assessment, $71.4 \%$ vs. $66.7 \%, P=0.643$ ).

\section{Effects on the Nepean Dyspepsia Index Questionnaire-Korean Version Reflux Symptom Scores in Elderly Patients}

The NDI-K reflux symptom scores in elderly patients are shown in Figure 5. The reflux symptom scores were significantly improved in the treatment group, but not in the control group (baseline vs. week 4 : DA-9701, $5.7 \pm 4.2$ vs. $3.3 \pm 2.9, P=$ 0.035 ; placebo, $6.8 \pm 6.9$ vs. $8.0 \pm 5.5, P=0.411$ ). Changes in the reflux symptom scores between the baseline values and those at week 4 were more significant in the treatment group than in the control group $(P=0.009)$. In the treatment group, changes in the reflux symptom score did not differ between elderly and non-elderly patients $(P=0.632)$.

\section{Adverse Events}

Of 42 patients in the treatment group, 1 patient vomited once. In addition, 1 patient had mild diarrhea and 1 patient had a mild cough in the control group. No other patients showed adverse events.
A

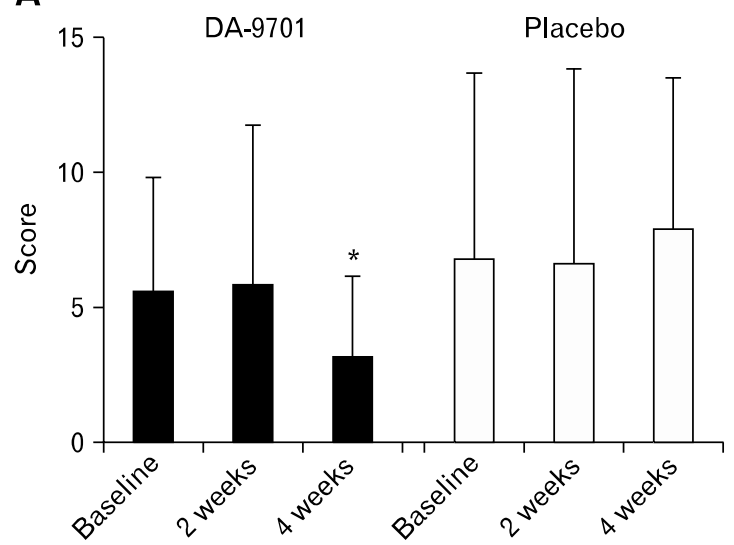

B

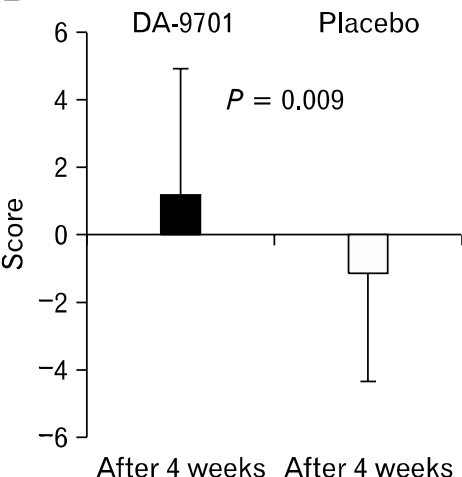

After 4 weeks After 4 weeks
Figure 5. Nepean dyspepsia index questionnaire-Korean version symptom score of 2 reflux symptoms (A) and changes from baseline (B) in elderly patients. ${ }^{*} P<0.05$ compared with score at baseline. 


\section{Discussion}

Although PPI is a mainstay of treatment in patients with NERD and in those with erosive esophagitis, whether minimal change esophagitis is an early endoscopic finding of erosive esophagitis remains controversial. ${ }^{9}$ A nationwide multicenter prospective study conducted in Korea demonstrated that the minimal changes were closely related with upper gastrointestinal symptoms and showed similar risk factors as those of gastroesophageal reflux disease (GERD). Therefore, it was suggested that minimal changes were considered as early endoscopic findings of GERD. ${ }^{3}$ However, another prospective multicenter study conducted in Korea showed that most of the endoscopic findings indicating minimal changes were not associated with GERD. ${ }^{29}$ In addition, patients with NERD have been suggested to be of heterogeneous group and different mechanisms may be responsible for their symptoms. ${ }^{9}$ Some patients experience heartburn caused by excess acid reflux, whereas others show esophageal chemoreceptor sensitivity to physiological amounts of acid. Another subgroup of patients may develop heartburn symptoms as a result of esophageal motor dysfunction. Hiatal hernia is less common and severe gastric atrophy is more frequently observed in patients with minimal change esophagitis than in those with erosive esophagitis. ${ }^{13,17}$ Moreover, PPIs are less effective in NERD patients than in those with erosive esophagitis patients. ${ }^{13-16}$ These findings suggest that the pathophysiology of minimal change esophagitis may be different from that of erosive esophagitis, and indicate that the development of more effective treatment options is necessary.

In the present study we assessed the efficacy of DA-9701, a newly developed prokinetic agent, in patients with minimal change esophagitis. Although DA-9701 improved the NDI-K symptom scores and quality of life scores after 4 weeks of treatment, an advantage of DA-9701 over placebo was not demonstrated. These results may be explained based on the ineffectiveness of DA-9701 in patients with minimal change esophagitis. However, the high placebo response rate in this trial might be another reason for the lack of a significant difference in efficacy between DA-9701 and the placebo. In our study, both of the proportions of patients who showed a response to the placebo according to the patients' and the investigators' global assessment were $66.7 \%$. A previous meta-analysis on GERD showed that the placebo response rate tended to increase in patients with NERD compared to those with erosive esophagitis (placebo response rate: NERD vs. erosive esophagitis, $18.31 \%$ vs. $11.87 \%, P=$ 0.246). ${ }^{30}$ Furthermore, the placebo response rates in patients with functional dyspepsia were $30-50 \% .{ }^{31-33}$ Because minimal change esophagitis patients who had symptoms including dyspepsia were included in the study, the placebo response rate was higher in our study than in previous studies on GERD. We believe that the high placebo response may have masked the differences in the efficacy of DA-9701 in patients with minimal change esophagitis.

We performed exploratory data analyses by dividing the patient population into various subgroups. The main purpose of this additional analysis was to identify low placebo response subgroups. The results showed that elderly patients aged 65 years or older had a low placebo response regarding reflux symptoms. DA-9701, however, showed similar efficacy on reflux symptoms between elderly and non-elderly patients. In addition, DA-9701 had an advantage on reflux symptoms over placebo in the subgroup of elderly patients. Despite the possibility of coincidental findings, we think that the efficacy of DA-9701 on reflux symptoms should be reinvestigated carefully in selected patients who do not respond to placebo.

Although this was a randomized, doubleblind, placebo-controlled study, there were several limitations. Firstly, several factors associated with the severity of symptoms in patients with NERD or erosive esophagitis, including hiatal hernia, atrophic gastritis, and Helicobacter pylori infection status, were not assessed. Although the randomized design of the study should minimize selection bias including hidden risk factors, an even distribution of all risk factors was not guaranteed. Secondly, we could not distinguish the patients with GERD from those with functional heartburn because 24-hour esophageal $\mathrm{pH}$ monitoring was not performed. Although such an exam is not a primary diagnostic option prior to treatment in patients with NERD, it would help to identify a subgroup of patients who would benefit from DA-9701 treatment. Thirdly, although we showed a low placebo response rate in elderly patients and an advantage of DA-9701 on reflux symptoms over placebo, it has not been proven that elderly patients generally have a lower placebo response rate than non-elderly patients. One previous study with pooled analysis, however, showed that elderly patients had a lower placebo response rate for migraine than younger patients. ${ }^{34}$ Our result, with a low placebo rate for reflux symptoms in elderly patients with NERD, should be supported by further studies.

Our results showed that DA-9701 did not improve the symptom scores nor quality of life scores in comparison with the placebo despite an improvement in the NDI-K symptom scores 
and quality of life scores after 4 weeks of treatment compared with baseline values in patients with minimal change esophagitis. The effect of DA-9701 on reflux symptoms in elderly patients, however, may be meaningful and merit further investigation.

\section{References}

1. Vakil N, van Zanten SV, Kahrilas P, Dent J, Jones R; Global Consensus Group. The Montreal definition and classification of gastroesophageal reflux disease: a global evidence-based consensus. Am J Gastroenterol 2006;101:1900-1920.

2. Hoshihara Y. [Endoscopic findings of GERD.] Nippon Rinsho 2004;62:1459-1464. [Japanese]

3. Lee JH, Kim N, Chung IK, et al. Clinical significance of minimal change lesions of the esophagus in a healthy Korean population: a nationwide multi-center prospective study. J Gastroenterol Hepatol 2008;23(7 Pt 1):1153-1157.

4. Kiesslich R, Kanzler S, Vieth M, et al. Minimal change esophagitis: prospective comparison of endoscopic and histological markers between patients with non-erosive reflux disease and normal controls using magnifying endoscopy. Dig Dis 2004;22:221-227.

5. Nakamura T, Shirakawa K, Masuyama H, Sugaya H, Hiraishi H, Terano A. Minimal change oesophagitis: a disease with characteristic differences to erosive oesophagitis. Aliment Pharmacol Ther 2005; 21(suppl 2):19-26.

6. Hongo M. Minimal changes in reflux esophagitis: red ones and white ones. J Gastroenterol 2006;41:95-99.

7. Tahara T, Shibata T, Nakamura M, et al. Presence of minimal change esophagitis closely correlates with pathological conditions in the stomach. Dig Dis Sci 2012;57:958-966.

8. Mishima I, Adachi K, Arima N, et al. Prevalence of endoscopically negative and positive gastroesophageal reflux disease in the Japanese. Scand J Gastroenterol 2005;40:1005-1009.

9. Fass R, Fennerty MB, Vakil N. Nonerosive reflux disease--current concepts and dilemmas. Am J Gastroenterol 2001;96:303-314.

10. Bate CM, Green JR, Axon AT, et al. Omeprazole is more effective than cimetidine for the relief of all grades of gastro-oesophageal reflux disease-associated heartburn, irrespective of the presence or absence of endoscopic oesophagitis. Aliment Pharmacol Ther 1997;11:755763.

11. Lind T, Havelund T, Carlsson R, et al. Heartburn without oesophagitis: efficacy of omeprazole therapy and features determining therapeutic response. Scand J Gastroenterol 1997;32:974-979.

12. Miner P Jr, Orr W, Filippone J, Jokubaitis L, Sloan S. Rabeprazole in nonerosive gastroesophageal reflux disease: a randomized placebo-controlled trial. Am J Gastroenterol 2002;97:1332-1339.

13. Carlsson R, Dent J, Watts R, et al. Gastro-oesophageal reflux disease in primary care: an international study of different treatment strategies with omeprazole. International GORD Study Group. Eur J Gastroenterol Hepatol 1998;10:119-124.

14. Galmiche JP, Stephenson K. Treatment of gastroesophageal reflux disease in adults: an individualized approach. Dig Dis 2004;22: 148-160.

15. Miwa H, Sasaki M, Furuta T, et al. Efficacy of rabeprazole on heart- burn symptom resolution in patients with non-erosive and erosive gastro-oesophageal reflux disease: a multicenter study from Japan. Aliment Pharmacol Ther 2007;26:69-77.

16. Dean BB, Gano AD Jr, Knight K, Ofman JJ, Fass R. Effectiveness of proton pump inhibitors in nonerosive reflux disease. Clin Gastroenterol Hepatol 2004;2:656-664.

17. Fass R. Epidemiology and pathophysiology of symptomatic gastroesophageal reflux disease. Am J Gastroenterol 2003;98:S2-S7.

18. Miwa H, Inoue K, Ashida K, et al. Randomised clinical trial: efficacy of the addition of a prokinetic, mosapride citrate, to omeprazole in the treatment of patients with non-erosive reflux disease - a double-blind, placebo-controlled study. Aliment Pharmacol Ther 2011;33:323332.

19. Hatlebakk JG, Johnsson F, Vilien M, Carling L, Wetterhus S, Thøgersen T. The effect of cisapride in maintaining symptomatic remission in patients with gastro-oesophageal reflux disease. Scand J Gastroenterol 1997;32:1100-1106.

20. Jung YS, Kim MY, Lee HS, Park SL, Lee KJ. Effect of DA-9701, a novel prokinetic agent, on stress-induced delayed gastric emptying and hormonal changes in rats. Neurogastroenterol Motil 2013;25: 254-259, e166.

21. Lee TH, Son M, Kim SY. Effects of corydaline from Corydalis tuber on gastric motor function in an animal model. Biol Pharm Bull 2010;33:958-962.

22. Hung TM, Na M, Dat NT, et al. Cholinesterase inhibitory and anti-amnesic activity of alkaloids from Corydalis turtschaninovii. J Ethnopharmacol 2008;119:74-80.

23. Hung TM, Ngoc TM, Youn UJ, et al. Anti-amnestic activity of pseudocoptisine from Corydalis Tuber. Biol Pharm Bull 2008;31: 159-162.

24. Lee TH, Choi JJ, Kim DH, et al. Gastroprokinetic effects of DA-9701, a new prokinetic agent formulated with Pharbitis Semen and Corydalis Tuber. Phytomedicine 2008;15:836-843.

25. Lee TH, Kim KH, Lee SO, Lee KR, Son M, Jin M. Tetrahydroberberine, an isoquinoline alkaloid isolated from corydalis tuber, enhances gastrointestinal motor function. J Pharmacol Exp Ther 2011;338:917-924.

26. Kim ER, Min BH, Lee SO, Lee TH, Son M, Rhee PL. Effects of DA-9701, a novel prokinetic agent, on gastric accommodation in conscious dogs. J Gastroenterol Hepatol 2012;27:766-772.

27. Lim CH, Choi MG, Park H, Baeg MK, Park JM. Effect of DA-9701 on gastric emptying in a mouse model: assessment by 13C-octanoic acid breath test. World J Gastroenterol 2013;19:43804385.

28. Talley NJ, Haque M, Wyeth JW, et al. Development of a new dyspepsia impact scale: the Nepean Dyspepsia Index. Aliment Pharmacol Ther 1999;13:225-235.

29. Kim JH, Park H, Lee YC; MIGHT study group. Is minimal change esophagitis really part of the spectrum of endoscopic findings of gastroesophageal reflux disease? A prospective, multicenter study. Endoscopy 2011;43:190-195.

30. Cremonini F, Ziogas DC, Chang HY, et al. Meta-analysis: the effects of placebo treatment on gastro-oesophageal reflux disease. Aliment Pharmacol Ther 2010;32:29-42.

31. Talley NJ, Locke GR, Lahr BD, et al. Predictors of the placebo response in functional dyspepsia. Aliment Pharmacol Ther 2006;23: 
923-936.

32. Moayyedi P, Soo S, Deeks J, et al. Systematic review: antacids, H2-receptor antagonists, prokinetics, bismuth and sucralfate therapy for non-ulcer dyspepsia. Aliment Pharmacol Ther 2003;17:12151227.

33. Blum AL, Arnold R, Stolte M, Fischer M, Koelz HR; The Frosch Study Group. Short course acid suppressive treatment for patients with functional dyspepsia: results depend on Helicobacter pylori status. Gut 2000;47:473-480.

34. Ho TW, Fan X, Rodgers A, Lines CR, Winner P, Shapiro RE. Age effects on placebo response rates in clinical trials of acute agents for migraine: pooled analysis of rizatriptan trials in adults. Cephalalgia 2009;29:711-718 